\title{
Çocuklarda Nadir Görülen Diyafragma Evantrasyonu
}

\author{
Rarely Seen Diaphragmatic Eventration in Children
}

\author{
Öner Özdemir' ${ }^{1}$ Taha M. Daştan² \\ ${ }^{1}$ Sakarya Üniversitesi Tip Fakültesi Çocuk İmmünoloji-Allerji BD, Eğitim ve Araştırma Hastanesi, Sakarya \\ ${ }^{2}$ Sakarya Üniversitesi Tip Fakültesi Çocuk Sağlı̆̆ı ve Hastalıkları Anabilim Dalı, Ass. Dr. Eğitim ve Araştırma Hastanesi Sakarya, Türkiye \\ Yazışma Adresi// Correspondence: \\ Öner Özdemir \\ Sakarya Eğitim ve Araştırma Hastanesi Çocuk İmmünolojisi Ve Alerji Hastalıkları Bölümü,Adnan Menderes Cad., Sağlık Sok. No: 195 Adapazarı, Sakarya, Türkiye \\ T: +902644445400 E-mail:ozdemir_oner@hotmail.com \\ Geliş Tarihi / Received : 20.03.2020 Kabul Tarihi / Accepted : 11.06.2021 \\ Orcid: \\ Öner Özdemir https://orcid.org/0000-0002-5338-9561 \\ Taha M. Daştan https://orcid.org/0000-0002-3825-7827 \\ ( Sakarya Tip Dergisi / Sakarya Med J 2021, 11(3):675-679 ) DOI: 10.31832/smj.706814
}

Öz

Konjenital diafragma evantrasyonu nadir görülen bir hastalık olup, klinisyen hekimlerce ayırıcı tanısı uygun șekilde yapıldıktan sonra gerekirse cerrahi tedavi uygulanan bir hastalıktır. Beș gündür prodüktif öksürük ve son 2 aydır geceleri yarım saatte bir uyanma șikâyeti ile çocuk polikliniğine başvuran 10 aylık erkek hasta sunulmaktadır. Hastanın dış merkezde çekilen akciğer grafisinde diyafragma elevasyonu görülmesi üzerine çocuk allerji ve immünoloji polikliniğine getirildi. Özgeçmişinde doğum sonrası 1. gününde morarma öyküsü ile yenidoğan yoğunbakım ünitesinde 2 gün takip edilme öyküsü mevcut. Son 2 aya kadar herhangi bir şikâyeti olmamıș. Akciğer tomografisi ve batın ultrasonu ile herniasyon, subdiafragmatik kitle ve tümöral olușum dıșlandı. Yenidoğan dönemindeki grafisine de ulașlan hastaya konjenital diafragma evantrasyonu tanısı konuldu. Asemptomatik seyrettiğinden cerrahi düşünülmedi ve takip önerildi. Nadir görülen bu olgu farkındalığı artırmak amacıyla burada sunulmaktadır.

Anahtar diafragma; eventrasyon; kronik öksürük; dispne.

kelimeler

Abstract

Congenital diaphragm eventration is a rare disease which can be surgically treated if necessary, after it is differentially diagnosed by clinicians. A 10-month-old male patient presented to outpatientpediatrics clinic with a complaint of productive cough for five days and waking half-hourly for twomonths is presented. Patient was taken to pediatric allergy and immunology clinics after his chest $x$-ray taken by an outside center showed a diaphragm elevation. There was a cyanosis on the first dayof birth and 2-days-follow-up at intensive care unit in his past medical history. Patient had nocomplaints until two months ago. With the chest tomography and abdominal ultrasonography,herniation, subdiaphragmatic mass and tumoral mass was ruled out. Having reached the chest $x$-rayof his neonatal period, the patient was diagnosed as congenital diaphragm eventration. As it wasasymptomatic, surgery was not considered and follow-up was suggested. This rare case is presentedhere to increase awareness.

Keywords diaphragma; eventration; chronic cough; dyspnea 


\section{GIIRIŞ}

Diyafragma evantrasyonu, kostodiyafragmatik bütünlügün sağlam olmasına rağmen kas tabakası iyi gelişmemiş diyafragmanın kalıcı yükselmesi (elevasyonu) olarak tanımlanabilir. ${ }^{1-3}$ Sıklıkla sol tarafta görülüp genellikle rastgele tespit edilir ve tanısı kolaydır. ${ }^{4}$ Etyolojisinde konjenital (doğuştan) nedenler veya edinsel (akkiz) frenik sinir paralizisi suçlanır. Diyafragma evantrasyonu nadir olup, görülme sıklığı $\% 0.05$ civarındadır. ${ }^{5}$

Konjenital olan tipinde diyafragmanın kas tabakası ileri derecede atrofik iken, frenik sinir zedelenmesine bağlı olan edinsel tipinde kas kitlesi normale yakındır. Edinilmiş frenik sinir paralizisi örneğin kalp cerrahisi veya toraks tüpü takılması sırasında oluşabilir. ${ }^{3}$ Konjenital diyafragma evantrasyonunda ise intrauterin enfeksiyon düşünülür. ${ }^{1}$ Sitomegalovirüs enfeksiyonu bilateral diyafragma evantrasyonuna neden olmakla birlikte konjenital kardiyak ve renal anomaliler de buna eşlik edebilir., ${ }^{3,4}$

Olgu serilerinden elde edilen veriler diyafragma evantrasyonu olan hastalarda klinik bulguların asemptomatikten şiddetli solunum sıkıntısına kadar gidebilen geniş bir yelpazede dağıldığını göstermektedir. ${ }^{6-8}$ En ağır vakalarda, solunum yetmezliği mekanik ventilasyon gerektirebilir. Bölgesel akciğer kompresyonu ve atelektazi nedeniyle tekrarlayan alt lob bronkopnömonisi riski de artmıştır.--9

Burada, konjenital diyafragma evantrasyonuna bağlı uzun süren öksürük şikâyeti olan hastamız nadir görülen bir bozukluğa sahip olduğundan sunulmaktadır.

\section{OLGU}

10 aylık erkek hasta 5 gündür süren öksürük ve gece uyuyamama şikâyeti ile çocuk uzmanına başvurmuştu. Çekilen posteroanterior (PA) akciğer grafisinde sağ hemidiyafragmada elevasyon görülmesi üzerine tarafımıza yönlendirilmişti (resim 1). Hasta geldiğinde genel durumu iyi, fizik muayenesi normaldi. Hastanın tartısı $9 \mathrm{~kg}$ (40.p), boyu $71 \mathrm{~cm}$ (26.p)'di. Dinlemekle akciğerler bilateral eşit hava- lanıyor ve ral-ronküs yoktu. Oksijen satürasyonu(\%98) ve dakika solunum sayısı (26/dak), normal sınırlarda idi.



Resim 1. Başvuru anındaki tek tarafl evantrasyonun görüntüsü

Kardiyak sistem ve batın muayenesi normaldi. Hastanınrutin biokimya testleri ve TORCH için bakılan antikorlar negatifti. PA akciğer grafisinde sağ diyafragmada hemielevasyon görüldü ve hepatik apse ve tümoral kitleleri dışlamak için tüm batın ultrasonu istendi. Subdiyafragmatikapse veya kitle oluşumu görülmedi. Hastanın çekilen kontrastsız akciğer tomografisinde diyafragma komşuluğundaki akciğer parankiminde minimal pasif atelektaziler görülmekle birlikte bronşiyal havalanma normal olarak değerlendirildi (resim 2). Kontrastsız kesitlerde üst batınorganlarında gross patoloji görülmedi.

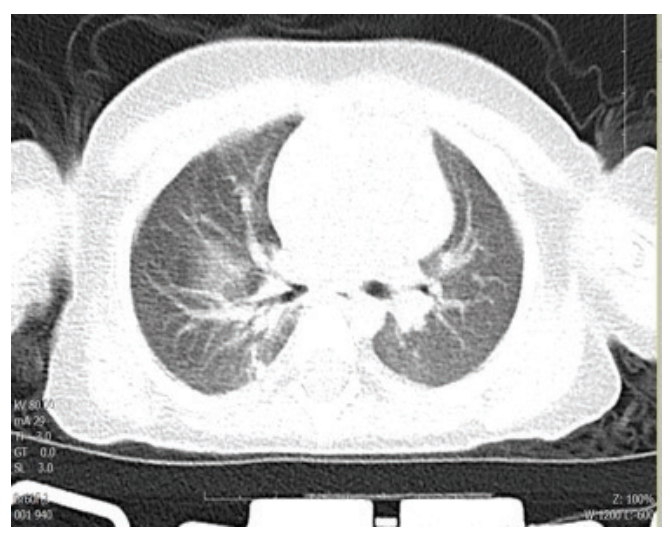

Resim 2. Diyafragma komşuluğundaki bronşiyal havalanmanin görüntüsü 
Hastanın ayrıntılı öyküsü alındığında ise doğduktan birkaç saat sonra morarma nedeni ile yenidoğan yoğun bakımda 3 gün takip edildikten sonra taburcu edildiği öğrenildi. Yenidoğan yoğun bakımda çekilen röntgenine ulaşıldığında ise orada da aynı şekilde sağ hemidiyafragmanın eleve olduğu görüldü (resim 3). Üç aylıkken kasık fitığından opere olan hastanın son 2 aydır başlayan geceleri 30 dakikada bir uyanma öyküsü olduğu öğrenildi. Hastanın PA akciğergrafisi ve akciğer bilgisayarlı tomografisi çocuk cerrahisine danışıldığında ise diyafragma evantrasyonunun asemptomatik olduğu ya da bu hastada daha ciddi semptomlara yol açmadığı sürece takip edilmesi önerildi. Olgu sunumu için aileye bilgi verilerek onam alındı.

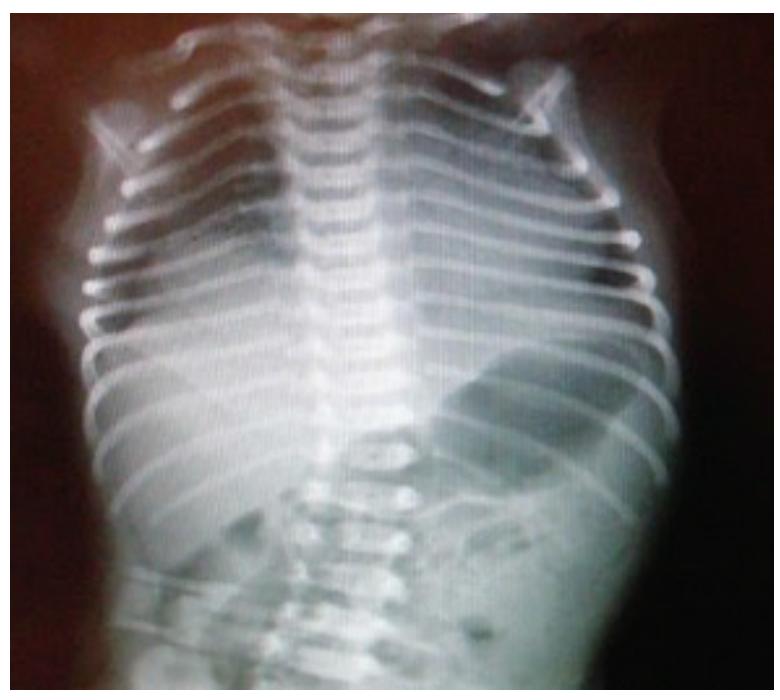

Resim 3. Yenidoğan döneminde să̆ hemidiyafragmada görülen evantrasyon

\section{TARTIŞMA}

Bebeklerdeki diyafragma evantrasyonu sık görülmeyen bir hastalıktır. Bu hastalık diyafragm kasının tamamının ya da bir kısmının fibroelastik dokuyla yer değiştirmesi sonucu oluşur. Bu da diyafragma ortasının daha ince ve mukavemetsiz olmasıyla sonuçlanır. Diyafragma evantrasyonunun bebeklerdeki insidansını tespit etmek zordur, çünkü lezyon sadece semptomatik hastalarda tanımlanır ve etkilenen bazı bebekler yıllar boyunca asemptomatik kalabilirler.
Diyafragma evantrasyonu; yukarıda bahsedildiği gibi, konjenital veya edinsel (atrofi vb.) nedenlerle olabilir. Konjenital evantrasyon diyafragm kasının yetersiz gelişiminden veya frenik sinirin olmamasından kaynaklanır. Diyafragmatik kasın tamamının ya da bir kısmının yerine fibroelastik doku geçmiştir. ${ }^{10-11}$ Diyafragma, devamlılı̆̆ını ve kosta kenarlarıyla bağlantılarını korur. Bununla birlikte zayıflamış diyafragma karın içi basıncının etkisiyle toraks içine yer değiştirerek akciğerlere bası yapar

ve solunumu zorlaştırabilir. Vakaların üçte ikisinde segmental defektler görülür ve en sık sağ hemidiyafragm etkilenir. ${ }^{6,7}$ Konjenital evantrasyon izole olabilmekle birlikte bazen hipoplastik akciğer, yarık damak, konjenital kalp hastalığı, situs inversus veya ürogenital anomaliler gibi gelişimsel anormallikler evantrasyona eşlik edebilir. ${ }^{6,712}$ Hastamızda yapılan fizik muayene, ultrasonik ve bilgisayarlı tomografik değerlendirmelerde ek patoloji saptanmamıştir.

Edinilmiş evantrasyonun en sık sebebi ise frenik sinir zdelenmesine bağlı diyafragma paralizisidir. Frenik sinir zedelenmesi, travmatik doğum ya da konjenital kalp hastalığ 1 için yapılan cerrahiden kaynaklanabilir. Edinilmiş evantrasyonda sağ ve sol hemidiyafragma eşit oranda etkilenir. ${ }^{6,712}$ Hastamızda doğum travması ya da cerrahi girişim yapılmadığından edinilmiş değil intrauterin enfeksiyone bağlı olmayan konjenital evantrasyon düşünülmütür. Literatürle uyumlu olarak sağ tarafta saptanmıştır.

Bebeklerde evantrasyon solunum sıkıntısı ve beslenme güçlüğü ile kendini gösterir. Semptomlar yenidoğan döneminde ve sonrasında herhangi bir yaşta başlayabilir. Önemli derecede diyafragma evantrasyonu olan bebek ve çocuklarda akut kalp, akciğer, mide ve barsak semptomları oluşabilir. Böyle durumlarda erken tanının hayati değeri vardır. ${ }^{13-15}$ Semptomların ciddiyetinde ne kadar erken ortaya çıktığg önemlidir. Büyük çocuklarda atelektazi, efor dispnesi olabileceği gibi iştahsızlık, kusma gibi nonspesifik 
bulgular da görülebilir. İleri yaşlarda hastalarda supin (sırt üstü) pozisyonunda yatma solunum sıkıntısına neden olabilir ve hatta hastalar bu sebeple oturma pozisyonda uyumak zorunda kalabilirler. Hastamızda aralıklı seyreden öksürük olmasına karşın solunumu rahattı. Sistem muayeneleri normal olmakla birlikte iştahı ve kilo alımı yaşınagöre normaldi. Yatarken yarım saatte bir sık sık uyanma öyküsü olan hastanın takibi önerildi.

Tanı çoğunlukla hastalarda PA akciğer grafisinde tesadfen diyafragmanın yüksek bulunmasıyla konur. Önemli olan bu evantrasyonun hastanın mevcut şikayetlerine nedenolup olmadığının ayırt edilmesidir. Standart PA akciğer grafisinde sağ hemidiyafragmanın sola göre $2 \mathrm{~cm}$ yüksek olması normal kabul edilmektedir ancak bundan fazla olanyüksekliklerde evantrasyon ayırıcı tanıları yapılmalıdır. Paradoksal diyafram hareketleri evantrasyona işareteder ve bu bulgu floroskopi veya toraks ultrasonu ile gösterilebilir. Bu yüksekliğe neden olabilecek diyafram altı abse veya torasik tümörler tomografi ile elimine edilmelidir. Hastamızda yenidoğan döneminde ve yeni çekilen PA akciğer grafilerinde sağ diyafragma sola göre $3-4 \mathrm{~cm}$ yüsek tespit edilmiştir. Batın ultrasonu ve akciğer tomografisi ile tümöral oluşum, apse ve diyafragma herniasyonu dışlanmıştır.

Ayırıcı tanıda öncelikli olarak hemidiyafragma yüksekliği ile seyreden konjenital diyafragma herniasyonu düşünülmelidir. Ancak lateral akciğer grafisi ile diyafragmatik bağlantıların yerinde olduğu gösterilerek herni ve evantrasyon ayrımı yapılabilir. Eğer kardiyomediastinal kayma veya torakstaki barsak dokusu nedeniyle grafi ile ayrım yapılamazsa toraks ultrasonu ile karın içine çıkıntı yapan barsakların herni kesesine mi yoksa evantrasyona mı bağlı olduğu anlaşılabilir. Eğer tüm görüntülemelere rağmen herni ve evantrasyon ayrımı yapılamazsa ameliyethanede doğrudan görüntüleme ile tanı konulur. ${ }^{16}$ Atelektaziler de diyafragma yüksekliğine yol açmakla birlikte atelektaziler diyafragmayı kendi tarafına çekerken evantrasyonda karşı tarafa doğru itilir. Vakamızda herniasyon akciğer tomog- rafisi ile dışlandı. Mediasten kayması görülmedi.

Cerrahi endikasyon kararında; gastrik volvulus gibi ciddi gastrointestinal komplikasyonlar, solunum desteği gerektiren (CPAP, mekanik vantilatör) konjenital defektler, yetersiz besin alımı ve tekrarlayan pnömoni olması önemlidir. ${ }^{17-18}$ Hastada hiçbir şikâyete yol açmaya evantrasyonlar için cerrahi tedavi gerekmez. Bu hastalarda tekrarlayan akciğer enfeksiyonları ve gastrointestinal semptomlar yoksa ve ciddi mediasten kayması tespit edilemiyorsa cerrahi tedaviye gerek yoktur. ${ }^{19}$ Hastalarda cerrahi tedavi endikasyonu oluşursa bu durumda da en sık başvurulan tedavi yöntemi plikasyondur. Plikasyonla tidal volüm arttırılırken diyafragma da stabil hale getirilmektedir. Paradoksal solunum engellenerek solunum mekaniği de böylelikle düzeltilmiş olur. Hastamızdaki diyafragma evantrasyonu uykuyu bozmasına rağmen, ciddi düzeyde semptomatik olmadığından cerrahi müdahale düşünülmedi.

Sonuç olarak; çocuklarda insidental olarak tespit edilen diyafragma evantrasyonunda ayrıntılı bir anamnez alınarak bu durumun komorbiditeye neden olup olmadığını anlamak önemlidir. Hastadaki diyafragma yüksekliğinin ayırıc1 tanısını doğru şekilde yaparak bu yüksekliğin evantrasyona mı yoksa apse veya tümöral oluşuma mı bağlı olduğu doğru tedavi yönlendirimi açısından gereklidir. Cerrahi lüzumu halinde ise minimal invazif girişimle yapılacakolan plikasyon yöntemi ile hasta konforu sağlanmalıdır. 
Sakarya Tip Dergisi 2021;11(3):675-679

ÖZDEMIR ve Ark., Diyafragma Evantrasyonu

\section{Kaynaklar}

1. Bașaklar C. Konjenital diyafram hernileri. 16. Bölüm, Bebek ve Çocukların Cerrahi ve Ürolojik Hastaliklar1 I. Cilt, 1th ed. Palme Yaytncllk, 2006:273-300.

2. Ackerman KG, Vargas $S O$, Wilson JA, et al. Congenital diaphragmatic defects: proposal for a new classification based on observations in 235 patients. Pediatr Dev Pathol 2012; 15:265-74.

3. Özkan S. Diyafram evantrasyonu ve cerrahi tedavisi. Journal of Clinical and Analytical Medicine, 2014: 88-98.

4. Işıł AF, Yalçınkaya İ, Kurnaz M. Erişkinlerde diyafragma yükselmeleri; cerrahi gerekli mi? Van Tip Dergisi 2002; 9:33-7.

5. Chin EF, Lynn RB. Surgery of eventration of the diaphragm. J Thorac Surg 1956; 32:6-14.

6. Wayne ER, Campbell JB, Burrington JD, Davis WS. Eventration of the diaphragm. J Pediatr Surg 1974; 9:643-651.

7. Wu S, Zang $\mathrm{N}, \mathrm{Zhu}$ J, et al. Congenital diaphragmatic eventration in children: 12 years' experience with 177 cases in a single institution. J Pediatr Surg 2015; 50:1088-92.

8. Deslauriers J. Eventration of the diaphragm. Chest Surg Clin N Am 1998; 8: 315-30.

9. París F, Blasco E, Cantó A, et al. Diaphragmatic eventration in infants. Thorax 1973; 28: 66-72.
10. Bisgard JD. Congenital eventration of the diaphragm. J Thorac Surg 1947; 16: 484-91.

11. Reed JA, Borden DL. Eventration of the diaphragm. Arch Surg 1935; 31:30-64

12. Smith CD, Sade RM, Crawford FA, Othersen HB. Diaphragmatic paralysis and eventration in infants. J Thorac Cardiovasc Surg 1986; 91:490-7.

13. Shah-Mirany J, Schmitz GL, Watson RR. Eventration of the diaphragm. Physiologic and surgical significance. Arch Surg 1968; 96:844-50.

14. Caffey J. Pediatric X-ray Diagnosis (5th ed.). Chicago: Year Book, 1967. P. 214.

15. Stephenson RH, Hopkins WA. Volvulus of the stomach complicating eventration of the diaphragm. Am J Gastroenterol. 1964; 41:225-34.

16. Karmazyn B, Shold AJ, Delaney LR, et al. Ultrasound evaluation of right diaphragmatic eventration and hernia. Pediatr Radiol 2019; 49:1010-1017.

17. Obara H, Hoshina H, Iwai S, et al. Eventration of the diaphragm in infants and children. Acta Paediatr Scand 1987; 76:654-8.

18. Kizilcan F, Tanyel FC, Hiçsönmez A, Büyükpamukçu N. The long-term results of diaphragmatic plication. J Ped Surg 1993; 28:42-4.

19. Doğruyol H. Çocukluk Çağındaki Diyafram Patolojileri. Bulletin of Thoracic Surgery (Toraks Cerrahisi Bülteni). 2013, 4(4):230-45 